Javier Molina

Sánchez

Fernando Vela

Cossio

Figura 1.Planta de situación. A la derecha, (1), presa de Poncebos. A la izquierda, (2), central de Arenas de Cabrales. Reelaboración propia a partir de ori ginal en el archivo histórico de Electra de Viesgo S.A. en E.On.

\section{Arquitectura e industria hidroeléctrica Las obras de Ignacio Álvarez Castelao y Juan José Elorza para Electra de Viesgo en Asturias}

Palabras clave: patrimonio industrial, presa, central hidroeléctrica, Álvarez Castelao, Juan José Elorza, Electra de Viesgo, Asturias.

La construcción de infraestructuras hidráulicas constituye uno de los ejes mejor conocidos de la politica económica del desarrollismo industrial en España desde comienzos de los años cincuenta. Sin embargo, pese a su elevado número e interés, éstas apenas se han estudiado desde el punto de vista arquitectónico. Este artículo estudia las características de las obras hidráulicas que proyectaron juntos el arquitecto Ignacio Álvarez Castelao y el ingeniero Juan José Elorza para la compañía Electra de Viesgo SA en Asturias y en Palencia durante los años cincuenta y sesenta del siglo $X X$. Todos los casos mencionados tienen en común la fructífera colaboración de distintos profesionales en un equipo multidisciplinar en el que se incluyeron la bellas artes.

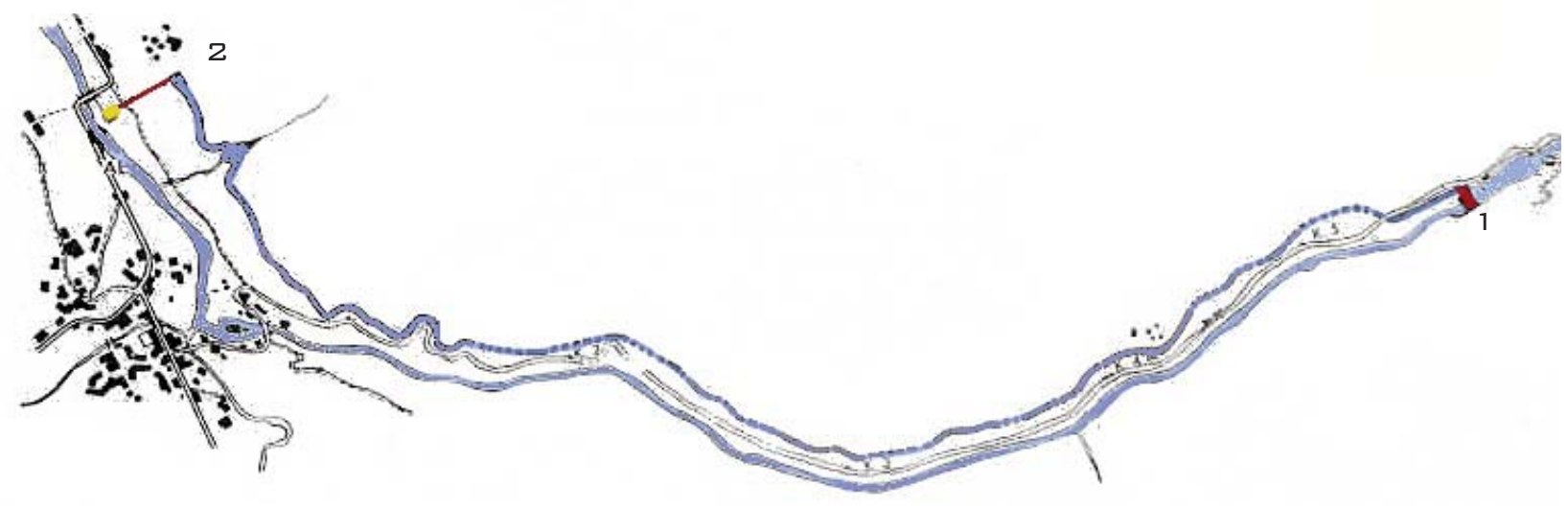

Javier Molina

Sánchez.Arquitecto.

Profesor de la

Escuela de

Cinematografia y Audiovisual de la Comunidad de

Madrid. Beca de doc torado de la

Fundación Juanelo Turriano.

Fernando Vela Cossío.Arqueólogo. Profesor Titular del Departamento de Composición

Arquitectónica de la ETSAM, UPM.

\section{Introducción}

as grandes transformaciones que expe-rimentó la sociedad española durante las etapas finales del Franquismo como consecuencia del importante desarrollo económico e industrial que se inicia a partir de 1959 produjeron también cambios muy señalados en nuestras ciudades y en nuestra arquitectura. Las obras de autores tan importantes como Francisco de Asís Cabrero (1912-2005), Rafael Aburto (19132014), Miguel Fisac (1913-2006), Alejandro de la Sota (1913-1996) o José Luis Fernández del Amo (1914-1995), servirian a la perfección para explicar el cambio de paradigma en el pensamiento arquitectónico español durante los años cin- cuenta y su enorme evolución a partir de los primeros años sesenta. El arquitecto asturiano Ignacio Álvarez Castelao (Cangas del Narcea 1910 - Oviedo 1984) representaria, en este contexto, una figura adelantada y muy significativa en ese cambio de mentalidad. Sus importantes trabajos en el campo de la arquitectura industrial, que ahora veremos, ejemplifican, de forma excepcional, la profundidad y la naturaleza de tan acusado progreso.

Como tan acertadamente tuvo oportunidad de señalar Javier Tusell en su estudio de 1987 sobre las distintas etapas del regimen del General Franco, "si hubiera que señalar una fecha cardinal en la historia española durante el periodo de Franco, sin 
duda [...] esa fecha sería 1959. En primer lugar, dicho año presenció un cambio fundamental en la politica económica a través del Plan de Estabilización, que a su vez hizo posible el desarrollo económico posterior. Dado el hecho de que el principal cambio acontecido en España durante la dictadura fue precisamente el paso de una sociedad agraria a otra industrializada, parece lógico apelar [...] a este tipo de criterio de carácter económico" (Tusell 1996: 249). Lo cierto es que entre 1951 y 1973 todos los países occidentales, y muy especialmente las economías europeas, van a vivir una etapa de señalado auge económico como consecuencia del intenso crecimiento del comercio mundial, alentado por la fuerte apertura al exterior de los países desarrollados. En este contexto, una economía autárquica como la española resultaba tan anacrónica como inviable. El deseo de cambio de la población española, el atraso relativo acumulado por el país, la liberalización de las importaciones, el crecimiento de la demanda tanto del consumo familiar como de la inversión privada y las exportaciones, la apertura al exterior y la existencia de recursos productivos, sobre todo financieros (apoyados tanto en el ahorro interno como en la inversión exterior) y las reservas demográficas procedentes del campo y de la población femenina, permitieron al país dar este gran salto adelante durante los años sesenta (Fuentes Quintana 1988: 9-13). Si durante la etapa 1948-1957 puede hablarse de una situación de pre-estabilización y del paso de una economía agrícola a una semiindustrializada, a partir del año 1959 el desarrollo condujo al país a un fuerte crecimiento, continuado y sostenido, muy cercano al $9 \%$ anual hasta 1964. Entre 1963 y 1969 España sería uno de los países del mundo con mejores resultados económicos, tan sólo por debajo de Japón (Tusell 1996: 257-259). Si la agricultura perdió entre 1950 y 1970 unos 2.400 .000 empleos, la actividad industrial manufacturera experimentaría un crecimiento, en ese mismo periodo, de 1.100 .000 trabajadores (Mateos y Soto 1997: 31), lo que puede dar idea suficiente de la magnitud del cambio.

Es en este contexto en el que debemos estudiar la construcción del importante conjunto de infraestructuras hidráulicas españolas. Estas constituyen uno de los pilares de la política económica que hizo posible el modelo de desarrollo industrial del régimen desde mediados de los años cincuenta hasta los primeros setenta, periodo en el que quedan enmarcados los valiosos ejemplos que vamos a estudiar detenidamente en este artículo.
Estas arquitecturas de la industria hidroeléctrica han sido hasta ahora poco estudiadas desde el punto de vista de los arquitectos que colaboraron en ellas, salvo en obras contadas, y casi siempre ocupan muy poco espacio en los trabajos de alcance general. En el caso concreto que nos interesa, aunque las obras de Castelao y Elorza aparecen (a excepción de la central de Aguilar de Campoo) y son recogidas sintéticamente en el Registro del DoCoMoMo Ibérico: La arquitectura de la industria, 1925-1965 (García, Landrove y Tostoes 2005: 120,121, 134), ningún otro libro ha tratado este tema con verdadera profundidad; las referencias se limitan a menciones de las obras como ejemplos menores o subsidiarios de otras obras de arquitectura consideradas más elevadas ${ }^{1}$. Además, se repiten de modo sistemático los conceptos compositivos, estéticos y funcionales ya recogidos en el mencionado Registro del DoCoMoMo.

Con estos antecedentes, este trabajo ha pretendido ofrecer una visión más amplia, completa e interrelacionada de estas interesantes obras de la industria hidroeléctrica, acercándose a ellas desde el análisis arquitectónico y aportando material inédito obtenido tanto de las visitas a los edificios en cuestión como del archivo histórico de la empresa Electra de Viesgo. ${ }^{2}$ Entre este material documental, de gran interés, cabe destacar todo el de naturaleza fotográfica y planimétrica que hemos encontrado de la central de Aguilar de Campoo, y que ahora, por primera vez, ve la luz.

\section{La Compañia Electra De Viesgo S.A.}

La empresa fue fundada en 1916 por un grupo de empresarios vascos, entre los que se encontraba el Banco de Vizcaya, que adquirieron la llamada "Sociedad General de Centrales Eléctricas", una empresa que suministraba energía eléctrica a Santander. ${ }^{3}$ A partir de 1920 expandieron el negocio a Asturias y Galicia con la adquisición de concesiones en los ríos Navia, Cares y Sil.

Durante la Guerra Civil varias de sus instalaciones fueron dinamitadas. Pero a partir de los años cincuenta y tras superar casi quince años de escasez presupuestaria, la empresa conocerá un importante auge con la construcción de las centrales de Arenas y Arbón y la ampliación de la presa y la central de Doiras. La compañía aprovechó las concesiones de grandes tramos obtenidas antes de 1939 para fines hidroeléctricos, en un momento en que la demanda de energía estaba aumentando con mucha fuerza, a una tasa anual en 
torno al 9\% en el año 1956, incluso a pesar de la escasa actividad industrial del país (Aguiló 2006: 150).

Electra de Viesgo también colaboró, junto a Hidroeléctrica del Cantábrico, en la construcción del salto de Grandas de Salime, para lo que formaron en 1945 una sociedad conjunta denominada Saltos del Navia que aún hoy se encarga de explotar el aprovechamiento hidroeléctrico. Además, absorbió otras compañias menores como Electra Pasiega, Electra Vasco Montañesa o la Compañia de Electricidad Montaña 4 y se asoció de nuevo con Hidroeléctrica del Cantábrico para construir la central térmica de Soto de Ribera. A partir de 1957 entró además en el mercado de la producción de energía nuclear con la creación con Iberduero de la empresa Nuclenor para la construcción y explotación de la central nuclear de Garoña, situada en el Valle de Tobalina, en Burgos (Madrazo 1981: 125131).

En 1991 la empresa fue comprada por Endesa, quien a su vez la revendió a la compañía italiana Enel en el año 2002. Finalmente, en 2008 la alemana E.On la adquirió. En el año 2006 era el quinto operador eléctrico por facturación del país, y contaba con seis centrales hidráulicas en Asturias, con una potencia total instalada de 189 megavatios (Tielve 2009:14).

\section{Arquitectura e Ingenieria: Ignacio Álvarez Castelao y Juan José Elorza}

Durante el periodo del desarrollismo la compañía Electra de Viesgo no sólo vivirá su momento de mayor esplendor económico, sino que además conseguirá, gracias a la colaboración de dos conocidas personalidades asturianas, el arquitecto Ignacio Álvarez Castelao y el ingeniero de caminos Juan José Elorza, ${ }^{5}$ construir una serie de presas y centrales hidroeléctricas que constituyen elementos de gran interés en el ámbito del patrimonio industrial español, tanto por su singularidad en aquello que concierne a su resolución formal como por contar con la partici-

Figura 2.

Central de Arenas de Cabrales. Vista exterior (Álvarez y Elorza 1962 23)

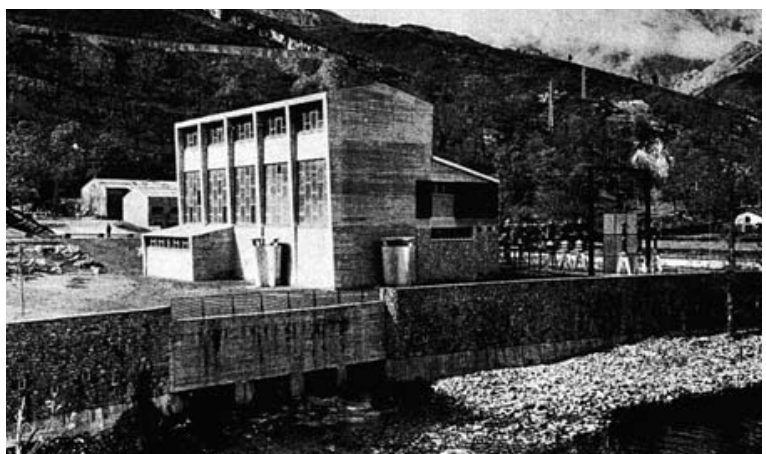

pación de un arquitecto con una sólida trayectoria profesional y una consolidada obra construida.

Ignacio Álvarez Castelao se formó como arquitecto en el ambiente de la vanguardia española de los años treinta. ${ }^{6}$ Trabajó para Electra de Viesgo en la construcción de varios poblados para los obreros de la eléctrica, y encontró tan atractivo el ejercicio de solucionar formal y paisajísticamente las obras hidráulicas, que insistió hasta que la empresa le dejó colaborar gratuitamente en ellas, siempre junto a su amigo Elorza (Arancón 1998: 256). Su adhesión al racionalismo y al Movimiento Moderno se hace evidente en casi todas sus obras (véanse, por ejemplo, el edificio Serrucho o la Facultad de Ciencias Geológicas de la Universidad de Oviedo, entre otros) pero más aún en sus edificios industriales donde, como afirma Natalia Tielve: "en arreglo a su propia naturaleza [en el caso de la arquitectura industrial] resultaba lógico recurrir a un lenguaje racional, basado en la lógica constructiva y tecnológica, donde la funcionalidad y la elementariedad primasen sobre la plasticidad" (Tielve 2007: 97). Se trata de amplios edificios con diáfanos interiores y abiertos al paisaje, donde se integran todos los elementos, desde el diseño de las luminarias hasta las jardineras que conforman el espacio exterior (Álvarez y Elorza 1960: 344).

Los proyectos en los que colaboraron Álvarez Castealo y Elorza, y que ahora vamos a analizar de forma detenida, son los de las centrales asturianas de Arenas de Cabrales (1952-1958), Silvón (1955-1958) y Arbón (1962-1969), y de la central de Aguilar de Campoo (1960-1963), situada en el norte de la provincia de Palencia. ${ }^{7}$

\section{Arenas de Cabrales}

La central se construyó para el aprovechamiento hidroeléctrico del río Cares. En la zona ya existía otra pequeña central, la de Camarmeña (cuya construcción entre 1917 y 1921 dio lugar a la conocida "ruta del Cares".8 El paisaje donde se enclava el conjunto, los Picos de Europa, es de una abrupta y sobrecogedora belleza, y fue preocupación principal de la empresa no dañarlo, cuidando tanto los volúmenes como los materiales. Así, se adopta el hormigón visto por su color, textura, ductilidad y fácil conservación. El propio Castelao comenta: "Las maravillosas calizas grises con ciertas manchas ocres rojizas y sus gigantescas formas fueron la preocupación de los proyectistas. El hormigón al natural, con sus pronunciadas 

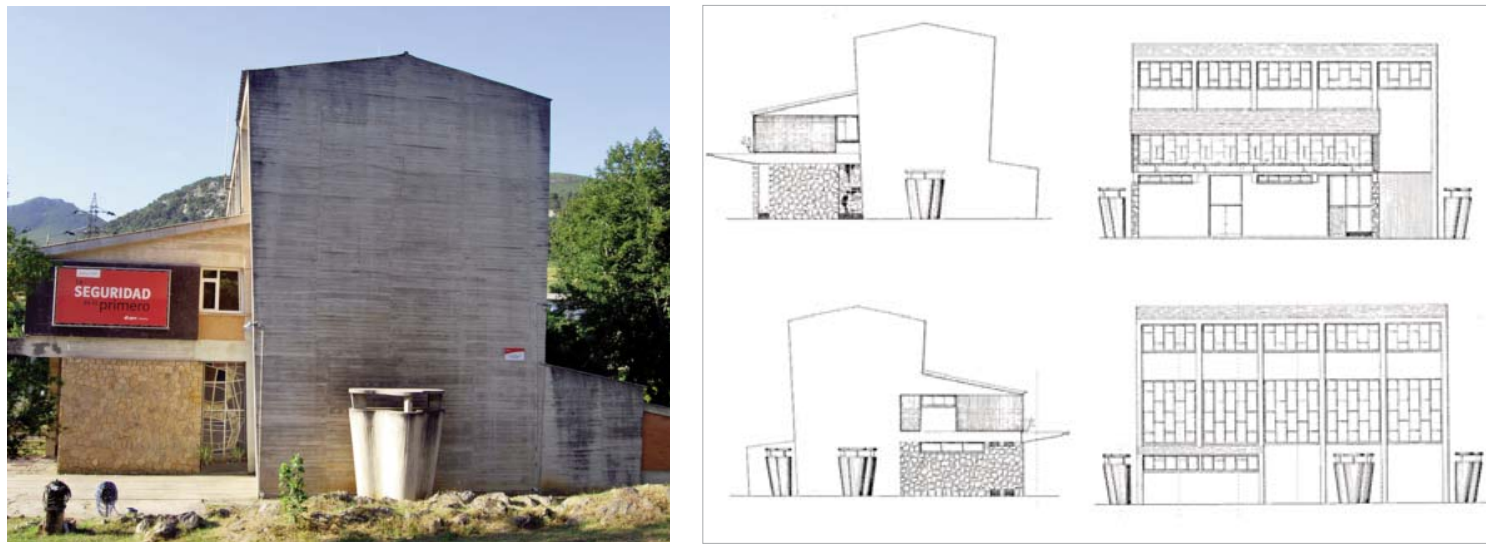

Izquierda. Figura 3. Central de Arenas de Cabrales, fachada sur. Se puede ver a la derecha una de las chimeneas de ventilación y a izquierda la vidriera de Antonio Suárez. Fotografia del autor (17 de agosto de 2013)

Derecha. Figura 4. Alzados de la central de Arenas de Cabrales. Archivo histórico de Electra de Viesgo S.A. en E.On

Figura 5. Central de Arenas de Cabrales. Vista interior de la entrada a la sala de mandos, con la vidriera a la derecha (Álvarez y Elorza 1962: 25) aristas, fue la solución adoptada. El revestimiento de gres en tonos ocre rojizos en algunas zonas ayuda a revalorizar el cemento." (Álvarez y Elorza 1960: 344) (figuras 1 y 2).

Se trata de un pequeño edificio con dos volúmenes (sala de máquinas y sala de control) en el que se busca la máxima transparencia a través de los espacios sin compartimentar y del tratamiento lumínico.La estructura es a base de pórticos de hormigón armado con pilares ligeramente troncocónicos, lo que hace que las fachadas laterales sean trapezoidales, parece como si el edifico quiera "echarse hacia delante". El cuidado diseño de los detalles (desde las luminarias de las oficinas hasta la jardinería, que busca "restablecer la Naturaleza", pasando por el generoso voladizo de hormigón que enmarca la puerta de entrada o el diseño de la liviana escalera de madera con estructura metálica, recurso que repetirán en todas las centrales), nos recuerda a las arquitecturas organicistas de Alvar Aalto ${ }^{9}$, y las ondulantes chimeneas de ventilación exteriores a las de la cubierta de la Unidad de Habitación de Le Corbusier (figuras $3 \mathrm{y}$ 4).

En este proyecto Castelao y Elorza contaron con la colaboración del pintor Antonio

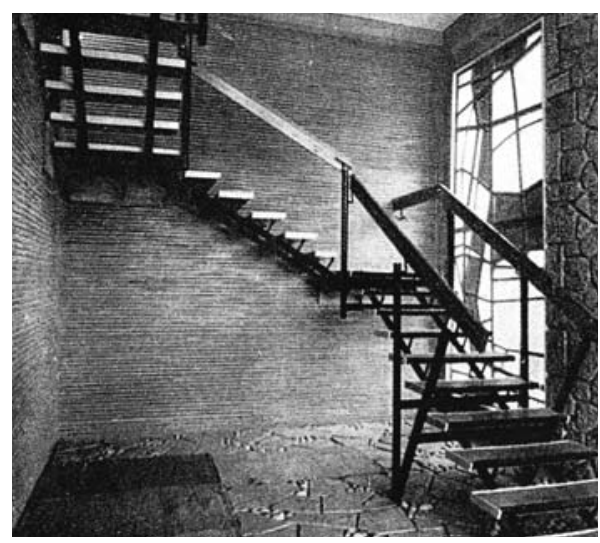

Suárez, que diseñó una vidriera decorativa en la entrada de la sala de mandos. ${ }^{10}$ Se trata de una ventana de sección trapezoidal de casi 4 metros de alto y 1,70 de ancho, que se subdivide con nervios de hormigón en pequeños vidrios irregulares de distintas texturas: trasparente, traslúcido, esmerilado, rayado...y cubiertos con plásticos de colores primarios (azul, amarillo y rojo) pegados a su superficie. La vidriera tiene un fuerte carácter constructivo a causa de la reticulación y a la fuerte presencia del hormigón en el que quedan rehundidos los vidrios, de tal manera que los nervios se convierten en las formas vertebradoras de una composición donde las posibilidades expresivas del color quedan parcial mente disminuidas (Gago 2008: 69-70, 84) (figura 5).

\section{Silvón}

El primitivo salto de Doiras fue construido sobre el río Navia entre 1929 y 1934. La intervención de Castelao y Elorza consistió en el recrecido de 4 metros de la presa original (sustituyendo los antiguos pináculos historicistas por unos atrevidos voladizos que rematan las antiguas pilastras que las sirvieron de base) (Aguiló 2005: 66), la reforma de la antigua central (en la que se creó una nueva entrada con una interesante escalera helicoidal), y la construcción de una nueva central al pie de la presa original. En cuanto a la primitiva central, Castelao realiza una actuación muy sutil: adosa al cuerpo original un nuevo acceso en hormigón con un gran ventanal de vidrio que recorre la fachada de arriba abajo. Se trata de un volumen que no intenta mimetizarse o copiar a lo ya existente, sino que, por el contrario, se adhiere a él con su nuevo lenguaje moderno, categorizando y dando valor al conjunto (figura 6).

Por otro lado, en la nueva central se vuelve a optar por el hormigón visto pero la solución constructiva resulta ser más osada que en Arenas de Cabrales, puesto que los muros de carga, ejecutados con un sistema análogo al del tapial sustituyen a los clásicos pórticos 
Figura 6. Escalera de entrada a la antigua central de Doiras. Fotografia del autor 26 de septiembre de 2012)

Figura 7. Central de Silvón, vista exterior desde el suroeste. Fotografia del autor (26 de septiembre de 2012)

Abajo izquierda. Figura 8. Central de Silvón, vista interior de la sala de máquinas, testero este. Las luminarias ya no funcionan, pero la sensación de sobrecogimiento que genera observar esta pared horadada por negros puntos que en su momento dieron luz, sigue muy presente. Fotografia del autor (26 de septiembre de 2012)

Derecha. Figura 9. Dibujo coloreado de la vidriera interior de Silvón. Reelaboración propia a partir de original en el archivo histórico de Electra de Viesgo S.A. en E.On.

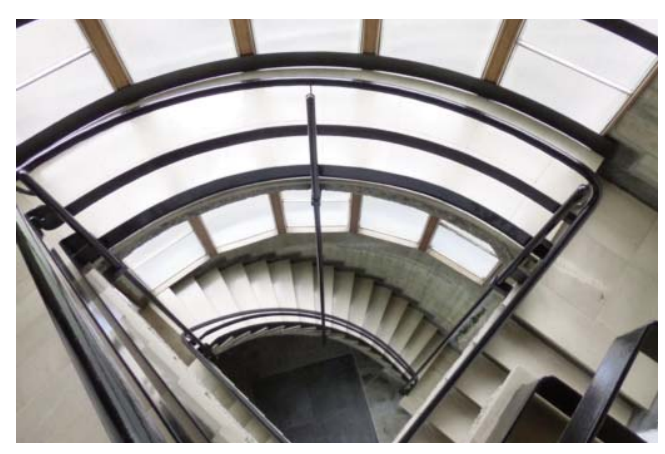

que han de soportar el puente grúa. Así, "los encofrados sirven de andamio y permiten el vertido del hormigón con carretillas. Con ello y con la modulación de los tableros se consiguió una gran economía de madera." (Álvarez y Elorza 1960: 344) (figura 7).

El resultado final es un contenedor, una caja, un paralelepípedo deformado por la cubierta inclinada en forma de $\mathrm{V}$ que enfatiza su carácter funcional y recio, con un interior amplio, limpio y sencillo. La decoración es extremadamente sobria y se limita a elementos muy puntuales. En el interior de la sala de máquinas, en el testero oriental, aprovechando los mechinales que dejan los encofrados al hormigonar, se introducen en esta retícula unas luminarias que constituyen un auténtico muro de luz, de tal manera que la pared queda iluminada por 42 lámparas de color negro que tienen forma de $\mathrm{V}$, como la cubierta (figura 8).

En la pared contraria, que se abre hacia el oeste, encontramos de nuevo una obra de Antonio Suárez: una enorme e impactante vidriera abstracta realizada con nervios de hormigón y plástico ${ }^{11}$ sobre la carpintería

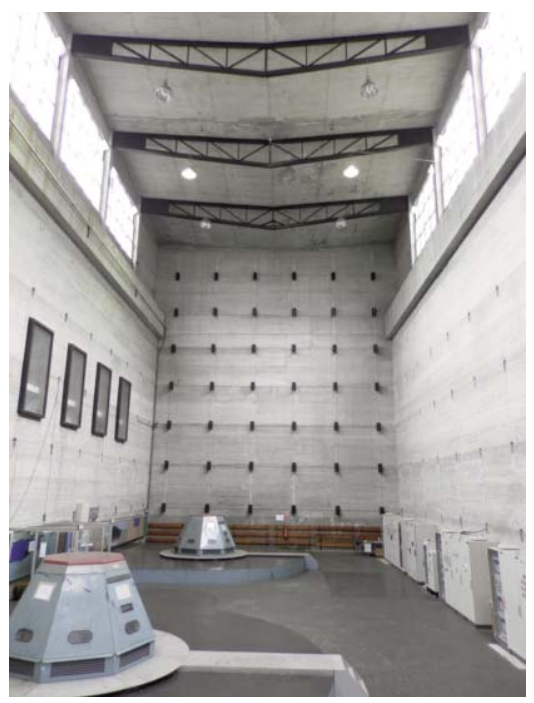

existente. Ocupa todo el alto de la sala de máquinas (unos 15 metros), y está dividido en dos por la viga de hormigón del puente grúa. La sensación que produce es la de encontrarse ante la vidriera de una iglesia, una auténtica catedral de la energía, donde la composición se llena de aristas y ángulos rectos para combinar los colores (azul, rojo, amarillo, verde), con una gran energía y expresividad (Gago 2008: 67), utilizando grandes gamas de azul y verde en el centro y reservando el rojo, desmembrado a base de diagonales, para los extremos (Tielve 2011: 130) (figura 9).

Suárez también participó en la central diseñando una escultura de la Virgen de Nuestra

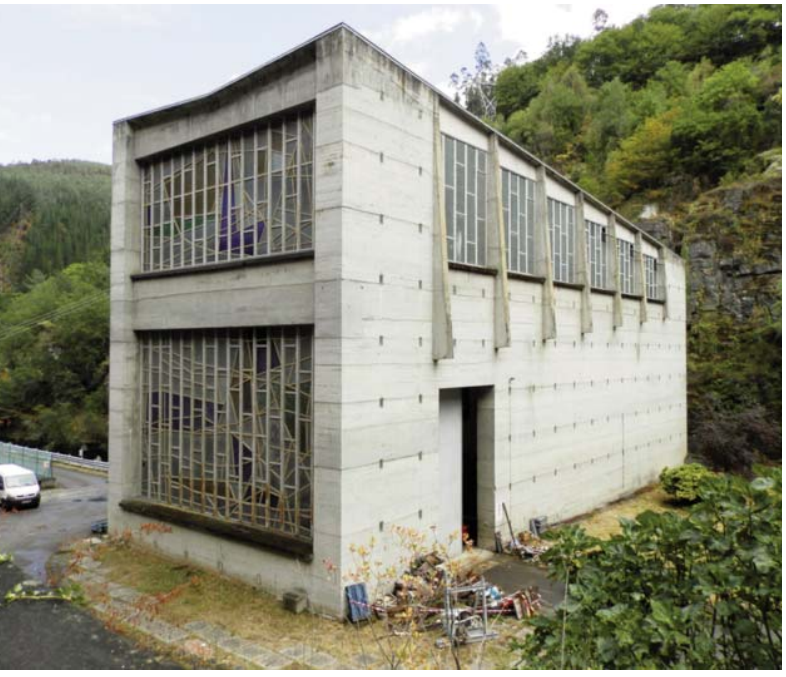

Señora de la Luz con varillas metálicas dobladas para el vestíbulo de la sala de control y con un friso (sería más bien un zócalo o un rodapié) que rodea la sala de máquinas en sus lados largos (norte y sur). Esta obra, de sintasol pegado a madera, está formada por fragmentos de colores vivos y contrastados en una combinación cromática en su tiempo violenta y a propósito disonante, ${ }^{12}$ pero que hoy

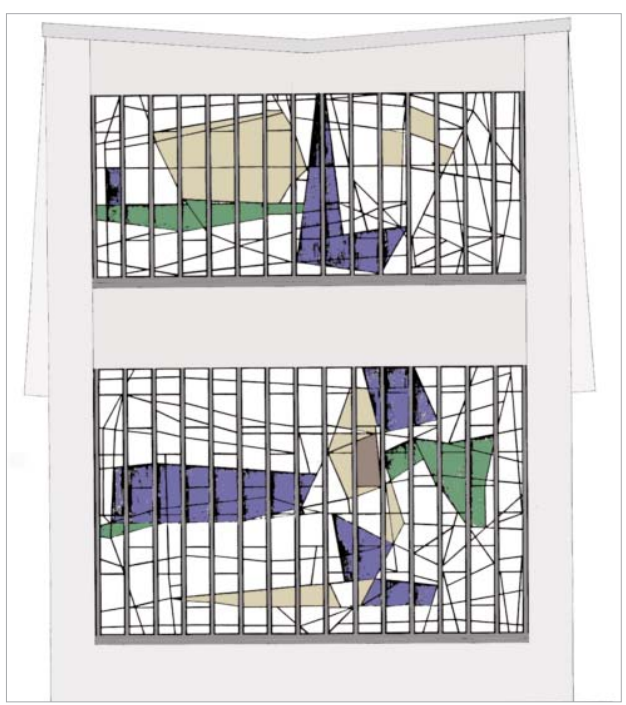


Figura 10. Central de Silvón, vista interior de la sala de máquinas, testero oeste. Puede verse parte del zócalo de sintaso en la pared derecha. Fotografia del autor (26 de septiembre de 2012)

Figura 11. Central de Silvón, alzado norte. La fachada de la sala de mandos se reviste con gresite, como en Arenas, pero de color marrón oscuro. Al fondo puede verse la presa de Doiras recrecida con los nuevos miradores de hormigón. Fotografia del autor (26 de septiembre de 2012)

Abajo izquierda. Figura 12. Planta de situación de la central de Arbón, a la derecha (1) La presa está situada al otro lado del meandro, a la izquierda (2).

Reelaboración propia a partir de original en el archivo histórico de Electra de Viesgo S.A. en E.On.

Derecha. Figura 13. Central de Arbón, vista de la fachada principal. En primer término puede verse la sala de control con su enorme ventanal acristalado.Fotogra fia del autor (26 de septiembre de 2012)

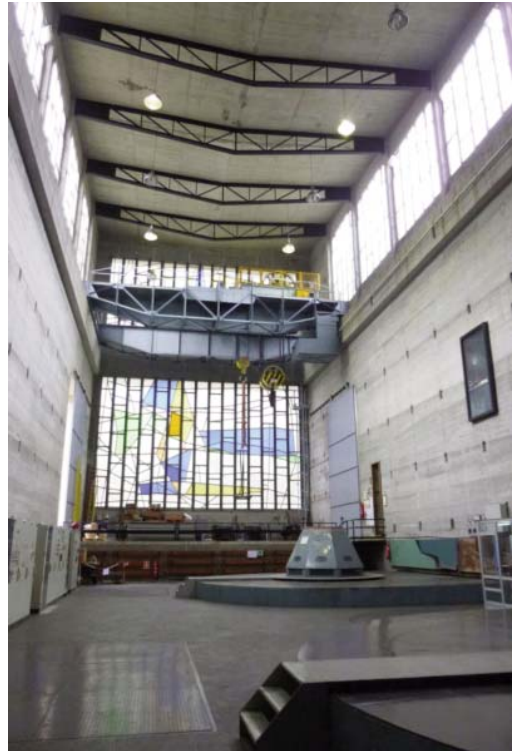

Arbón

En la construcción de este salto, Castelao y Elorza recogen toda la experiencia asimilada en los anteriores encargos, llegando a una pureza de las formas y una simplicidad asombrosas. Se trata de un auténtico ejercicio de estilo, de un edificio Racionalista de manual. Por su adaptación formal, la disposición e interrelación de los volúmenes, la magistral distribución de los huecos, los materiales empleados, los grandes paños acristalados, las cubiertas planas, la abstracción figurativa... podemos ver un repertorio formal con claras referencias a la obra de Mies (GarcíaPola 1997: 95). El hormigón bruñido, el gresite blanco, el vidrio, la carpintería metálica pintada y la madera se combinan en un contraste de texturas perfectamente modulado que armoniza el conjunto (figuras 12 y 13).

está deslucida debido al deterioro causado por la humedad y la falta de mantenimiento, y que queda parcialmente oculto por la diversa maquinaria que allí se acumula (figura 10).

Estas son las únicas concesiones a la decoración en un edificio donde se busca que el hormigón en bruto, con sus aristas y sus texturas sea el gran protagonista. 13

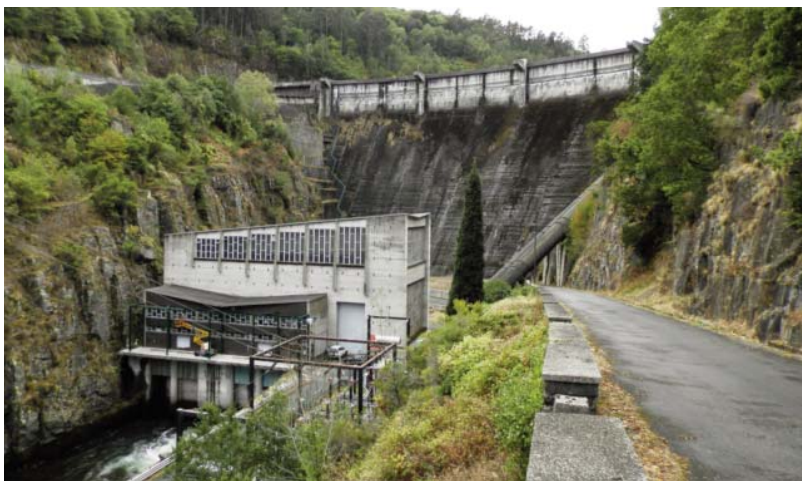

Al igual que en Arenas, la sala de mandos y oficinas es un volumen diferenciado que se vincula al cuerpo principal de la sala de alternadores. En este caso, la cubierta en forma de $\mathrm{V}$ se repite, pero se ejecuta perpendicular al lado corto, con lo que el aspecto de gaviota que alza el vuelo es muy acusado, más teniendo en cuenta que se trata de un volumen que se construye en voladizo sobre el canal de desagüe de la presa (figura 11).

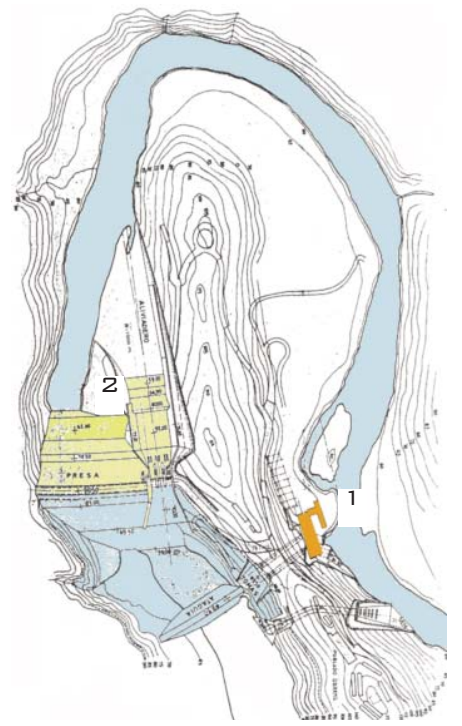

La sala de control es un volumen alargado y liviano, con grandes ventanales de cristal orientados al paisaje, elevado en altura a modo de pasarela entre la sala de alternadores y las dependencias auxiliares, al que se sube por un pequeño pabellón de cristal con una escalera exenta de madera (recurso ya utilizado en Arenas de Cabrales), y que se relaciona fisicamente con la sala de alternadores mediante un gran ventanal situado al fondo de la sala de mandos.

La sala de máquinas es una nave única de 60 $\mathrm{m}$ de longitud cubierta por medio de una sucesión de bóvedas de hormigón, en cuyos extremos se colocan vidrieras por las que penetra una luz lateral difusa. La fachada

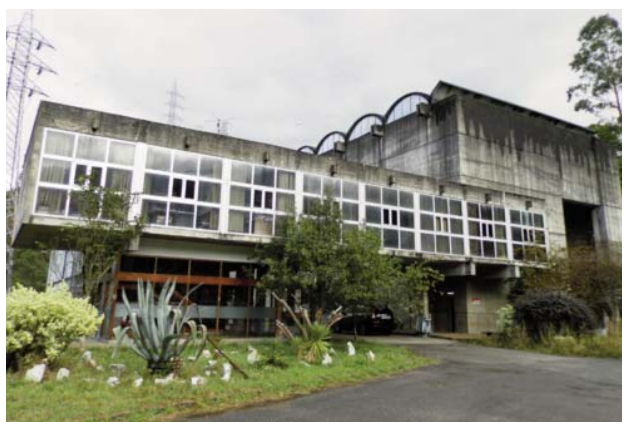



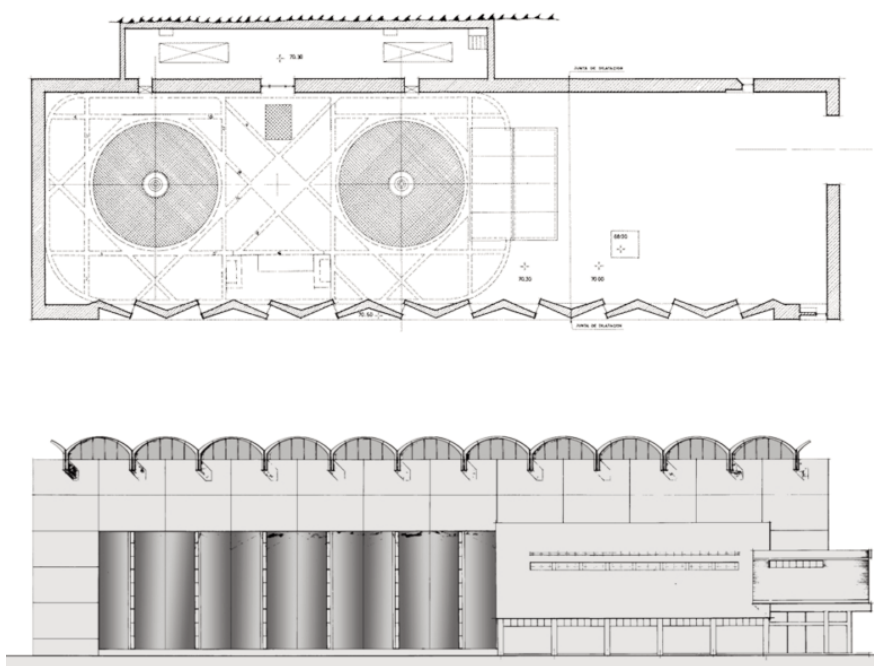

Izquierda. Figura 14 Planta y alzado de la sala de máquinas de la central de Arbón. Reelaboración propia a partir de original en el archivo histórico de Electra de Viesgo S.A. en E.On

Derecha. Figura 15. Central de Arbón, vista interior de la sala de máquinas. Fotografia del autor (26 de septiembre de 2012)

Izquierda. Figura 16. Central de Arbón, vista interior de la sala de turbinas. Ángel Sanchis en Registro del Docomomo Ibérico: ficha AST.17.0

Derecha. Figura 17. Central de Aguilar de Campoo, sección de la presa y la central por la sala de máquinas y el canal de desagüe. Puede apreciarse la relación de escala entre presa y central. Reelaboración propia a partir de original en el archivo histórico de Electra de Viesgo S.A. en E.On. está compuesta por unas singulares piezas verticales de hormigón plegadas en ángulo de $120^{\circ}$ con forma de " $v$ " invertida colocadas en forma cóncava o convexa ${ }^{14}$ y desplazadas en su eje horizontal para permitir aberturas de luz indirecta, consiguiendo una iluminación interior homogénea (García, Landrove y Tostoes 2005: 134). Este mismo modelo de pieza a otra escala sería utilizada por Castelao para diseñar todo el espacio exterior adyacente a la central, desde las jardineras hasta el vallado de la finca. Al fondo de la sala, rompiendo la sobriedad del muro ciego de hormigón, un gran ventanal se abre hacia el paisaje de ribera que rodea el salto (figuras 14 y 15).

La sala de turbinas es otro de los elementos singulares de esta central. Debido a la poca altura del salto, los grupos disponen de un eje intermedio que permite ganar más altura y potencia. De esta manera, la sala situada bajo los alternadores tiene una excepcional altura de casi nueve metros (de las mayores del mundo), donde las turbinas quedan

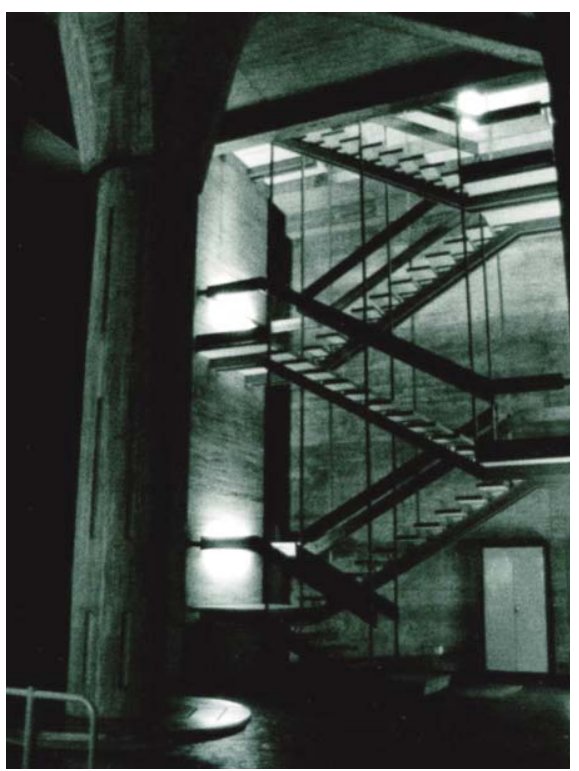

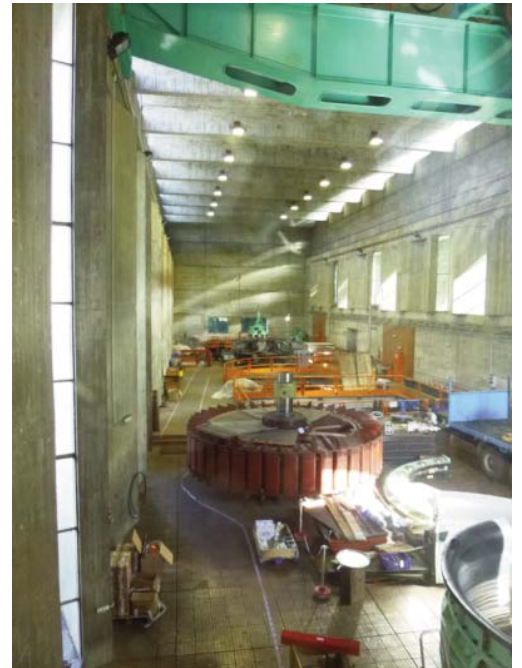

embebidas dentro de esbeltos pilares de hormigón en forma de columnas con capiteles campaniformes. Estas formas recuerdan a las que utilizó Frank Lloyd Wright en el S. C. Johnson and Son Company Administration Building, construido entre 1936 y 1939 (Garcia, Landrove y Tostoes 2005: 134) (figura 16$)$.

Es un lenguaje formal mucho más cercano a Louis I. Khan o al Le Corbusier brutalista, por el tratamiento del hormigón y las posibilidades que ofrece la iluminación como medio para generar emociones. Como dice Miguel Ángel García-Pola: "La sensación de sacralización que propicia el interior de estos edificios industriales, verdaderos templos de la energía, donde la maquinaria se ensalza en vez de esconderse, se aprecia de manera especial en Arbón. [...] Todos los gestos expresivos dependen del tratamiento que recibe la luz natural y el diseño estructural de sus elementos" (Garcia-Pola 2002: 99).

\section{Aguilar de Campoo}

Nos encontramos ante una obra que parece haber sido injustamente olvidada, que apenas aparece mencionada en las notas a pie de página de libros y artículos. Sin embargo, es

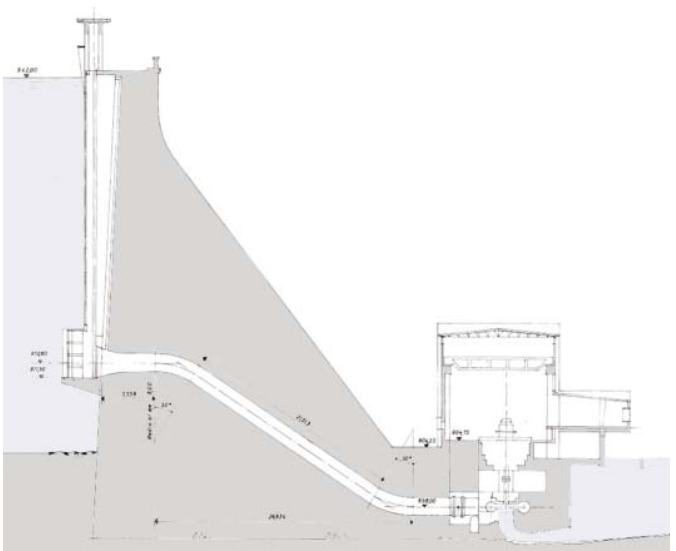




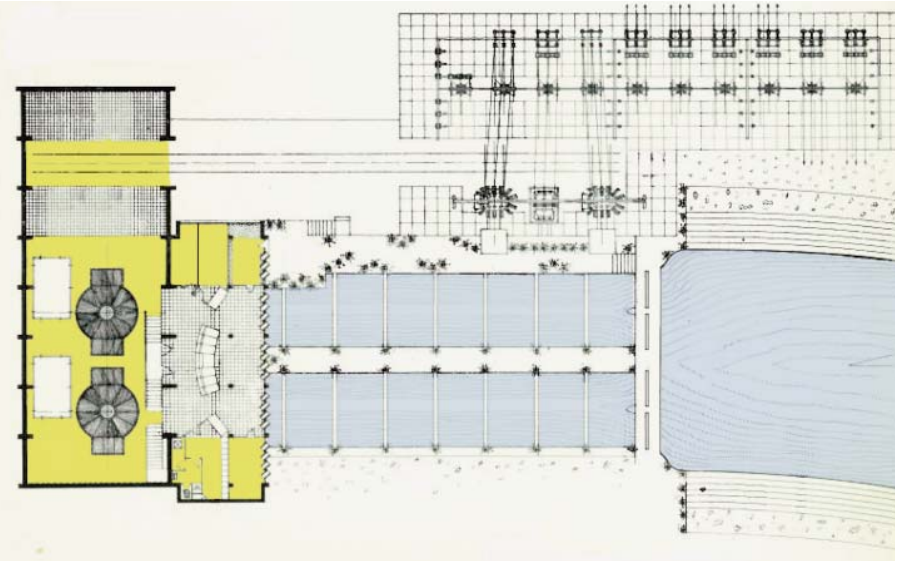

Figura 18. Planta de la central de Aguilar de Campoo. En el dibujo pueden verse todos los elementos perfectamente diseñados, desde el pavi mento hasta las jardines del pequeño jardin delante del edificio. Reelaboración propia a partir de original en el archivo histórico de Electra de Viesgo S.A. en E.On.

Arriba Derecha. Figura 19. Central de Aguilar de Campoo, vista exterior. Al fondo puede verse la pared de la presa que ya estaba construida cuando se rea lizó la central. Fotografia del autor (15 de mayo de 2013)

Derecha. Figura 20. Central de Aguilar de Campoo, vista interior de la sala de máquinas. Fotografía del autor 15 de mayo de 2013)

Figura 21. Central de Aguilar de Campoo, detalle de las cajas de hormigón armado con fibra de vidrio que sirven para iluminar indirectamente los distintos espacios. Fotografia del autor (15 de mayo de 2013) muy interesante el uso que Castelao y Elorza hacen aquí de los recursos estéticos y funcionales que ya aplicaran en sus proyectos anteriores. Así, de nuevo nos encontramos con temas recurrentes como el problema de la doble escala (el edificio de la central frente a la pared de la presa), el empleo del hormigón y el gresite, la sinceridad constructiva, el uso de la luz y el claroscuro entre los paños perfectamente modulados, etc... (figura 17).

Al igual que en Arenas, Silvón y Arbón, la central se compone de dos volúmenes, de tal manera que la sala de control se adelanta respecto de la nave, con un voladizo sobre el canal de desagüe. El desplazamiento en planta entre los dos volúmenes y la situación de los accesos, frontales, cercanas al extremo y a distinta altura, producen una curiosa asimetría en el conjunto, acentuada por la dirección de las celosías y carpinterías (Arancón 1998: 256) (figuras 18 y 19).

Pero lo más sorprendente de este edificio se halla en su interior, en su sala de máquinas donde, con unos mínimos elementos (los materiales: hormigón, ladrillo, vidrio; y la construcción: sencilla y sincera), se consigue una sensación espacial sobresaliente, sobre todo al contemplar los testeros cortos, unas altísimas paredes ciegas en las que se recrea un aparejo de sogas y tizones (donde éste sobresale generosamente de la vertical del muro), iluminados de forma indirecta por unos paralelepípedos de hormigón con fibra de vidrio girados 45 grados con respecto al eje vertical situados en la fachada a levante. El juego de texturas y de claroscuros demuestra que ésta es una actuación atrevida e inteligente, llevada a cabo con una escasez de medios que la hace aún más interesante (figura 20).

Estos elementos prefabricados serán el leit motiv de este proyecto, puesto que además, serán utilizados para la facha-

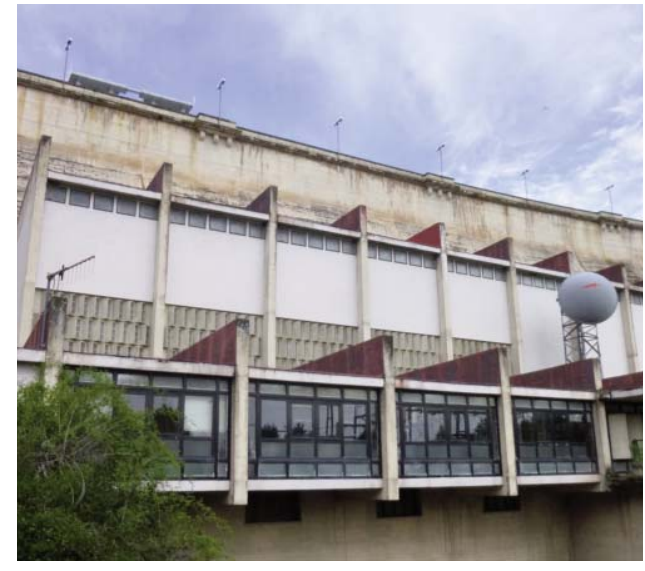

da de la sala de mandos (aunque hoy día han desaparecido casi todos y sólo se conservan tres en el vestíbulo), y también para el tratamiento del espacio exterior (utilizándose como jardineras) (figura 21).

De este modo vemos, en la última colaboración entre Castelao y Elorza, ${ }^{15}$ cómo han conseguido una integración tan sutil de las Artes que no es necesaria siquiera la existencia de elementos decorativos y son los propios materiales y su capacidad plástica los que nos remarcan la contundente expresividad que pueden llegar a tener los edificios industriales.

\section{Luz, espacio, arquitectura, paisaje}

Del análisis de los ejemplos estudiados resulta inevitable deducir que cada proyecto de
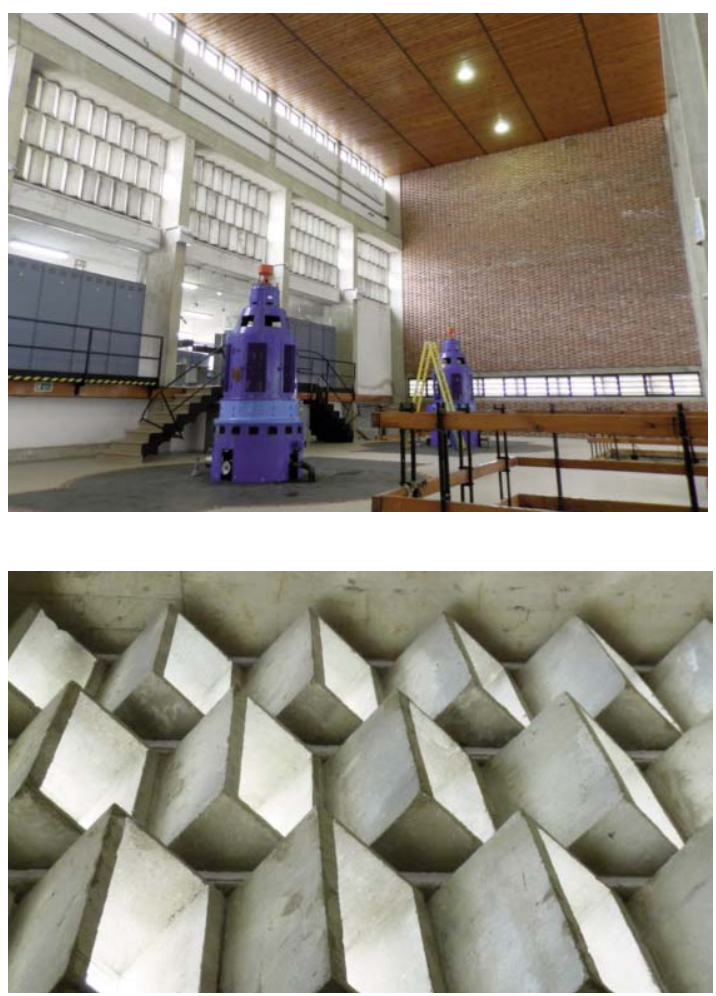
Figura 22.Centrales de Silvón y Aguilar. Tratamiento de texturas en los testeros de la sala de alternadores. Fotografias del autor $(26 /$ sept/ 2012 y 15/may/2013)
Álvarez Castelao y Elorza para Electra de Viesgo corresponde inequívocamente al lugar en el que se localiza y al programa específico que desarrolla. Castelao no acomete del mismo modo todos estos edificios. Cada uno es pensado y diseñado atendiendo a las necesidades planteadas y a los condicionantes existentes, aunque estos ejemplos (como toda su obra en general) transmitan una coherente y firme linea de pensamiento, muy vinculada al Movimiento Moderno, que toma distancia de los cánones impuestos a la arquitectura oficial durante la primera etapa de la Dictadura

Conceptos como el tratamiento de la luz, la composición de los espacios, los materiales utilizados, la modulación, la relación con la escala de paisaje... se repiten en cierta manera en las obras de Castelao, donde el arte y la tecnología van de la mano, como decía el ingeniero Gaetano Minnucci, "armonizando la relación entre forma y posibilidad técnica y forma y exigencia práctica" (Vittorini 1998).

Por un lado, la iluminación es un elemento fundamental para la caracterización de los espacios industriales. Son los materiales (fundamentalmente el hormigón con sus múltiples facetas y acabados, pero también el vidrio, el gresite, la madera...) los que determinan con su forma y posición cómo se va a iluminar, siempre de manera indirecta, cada estancia. Así nos encontramos ante la luz tamizada que atraviesa una vidriera en Silvón y Arenas o frente a la luz etérea que se filtra entre los módulos de hormigón seriados de Arbón y Aguilar, convenientemente distribuidas para que la iluminación siempre sea difusa. Además, las ventanas, con su proporción decididamente estrecha, vertical y contrapeada en las particiones entre distintos montantes, acentúan la sensación de encontrarse en

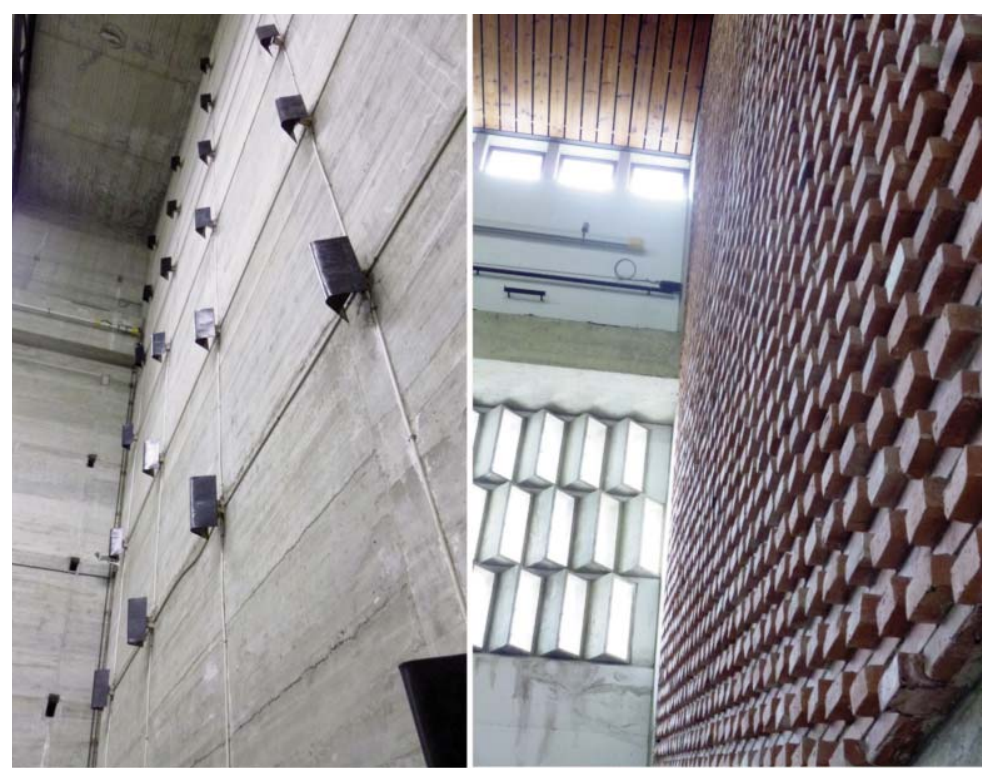

un espacio funcional, pautado y rítmico como corresponde a una fábrica. Las centrales de Castelao se caracterizan por el empleo del hormigón visto como material cuya expresividad plástica aporta importantes valores estéticos a las construcciones industriales. No obstante, esto no le impide emplear otros materiales para configurar los espacios interiores. En Silvón y Aguilar de Campoo encontramos un gesto similar en el tratamiento del interior de la sala de alternadores. En Silvón recurre a la repetición de un elemento, una pequeña luminaria en forma de $\mathrm{V}$, por toda una pared de la gran sala. Mientras que en Aguilar de Campoo, decide emplear ladrillo para crear una textura con volumen a través del empleo de un aparejo singular, generándose un rico contraste de sombras (figura 22).

Otro de los factores iterativos es el cuidado diseño de todos los elementos decorativos del edificio, desde los tiradores de las puertas (en Aguilar, por ejemplo, son antiguas traviesas de un ferrocarril minero que existía en el lugar), hasta las luminarias de las oficinas (en Arbón se trata de globos montados sobre un sencillo bastidor metálico plano y rectangular pintado de rojo), vinculados además a la propia estructura del edificio y a la búsqueda constante de la sinceridad constructiva (por ejemplo, en Doiras la zanca de la escalera deja a la vista la pizarra, una piedra local, empleada como árido del hormigón). En Silvón las jardineras tienen forma de V (como la cubierta), así como en Arbón las vallas de protección exterior repiten la estructura de la sala de mandos o en Aguilar se utilizan para ordenar los jardines adyacentes a la central. Además, se repiten o reutilizan elementos compositivos, por ejemplo, en Silvón ya aparecen (en el vestíbulo de entrada a la sala de mandos) los mismos paralelepípedos que usaria en Aguilar para hacer sus cajones de luz (figura 23) a plena integración de las Artes $^{16}$ (arquitectura, escultura, pintura y, en el caso de las construcciones industriales, también la ingeniería) es patente en todos los proyectos, aunque con una contención estética muy importante, dejando sólo los elementos decorativos esenciales y necesarios. Como él mismo comenta: "Actualmente las Empresas Hidroeléctricas cuidan mucho la presentación de sus instalaciones, y por este camino se ha llegado a recargar con exceso la decoración de las mismas, por lo que hemos creído conveniente simplificar en honor a la sencillez y a la conservación" (Álvarez y Elorza 1962: 25). ${ }^{17}$ Para Castelao debía reducirse la presencia de todo elemento que pudiera distraer la mirada de la apreciación de la arquitectura afirmándose así en la tendencia al uso del hormigón armado visto y a la minima decoración, basada ésta además en unos elementos muy sencillos y una depurada abs- 

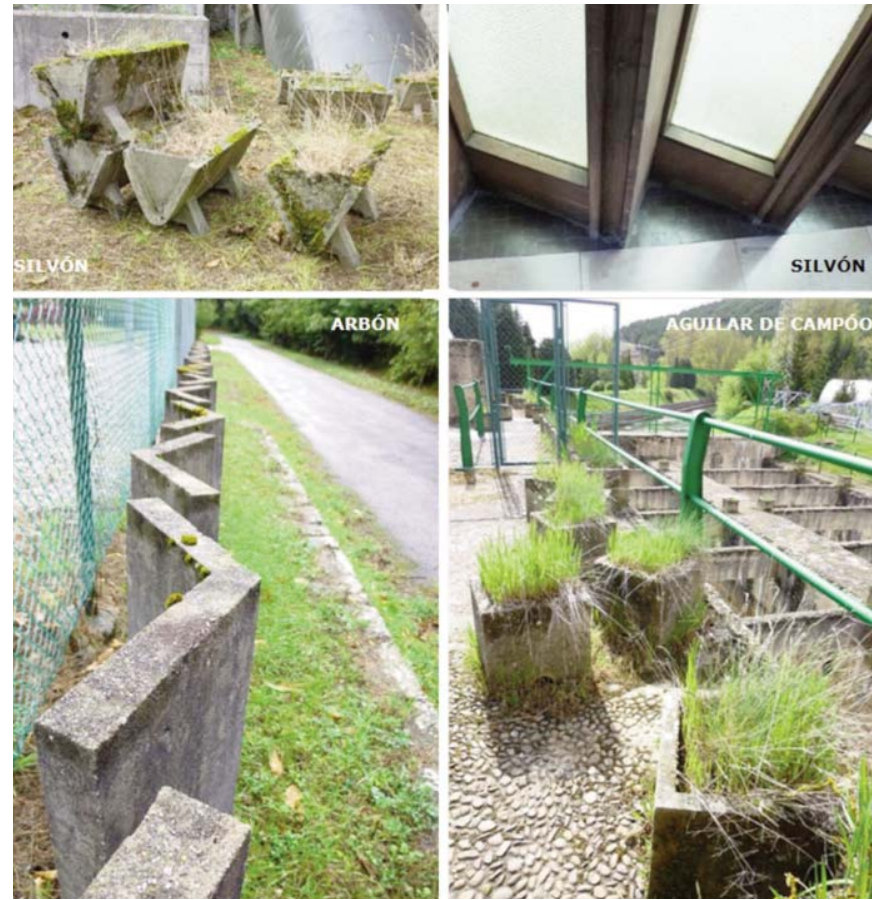

Figura 23. Detalles de las centrales de Silvón, Arbón y Aguilar. Fotografias del autor

(26/sept/2012 y $15 /$ may/2013)

Figura 24. Centrales de Silvón y Aguilar vistas desde la coronación de la presa. Fotografias del autor (26/sept/2012 y 15/ may/2013)
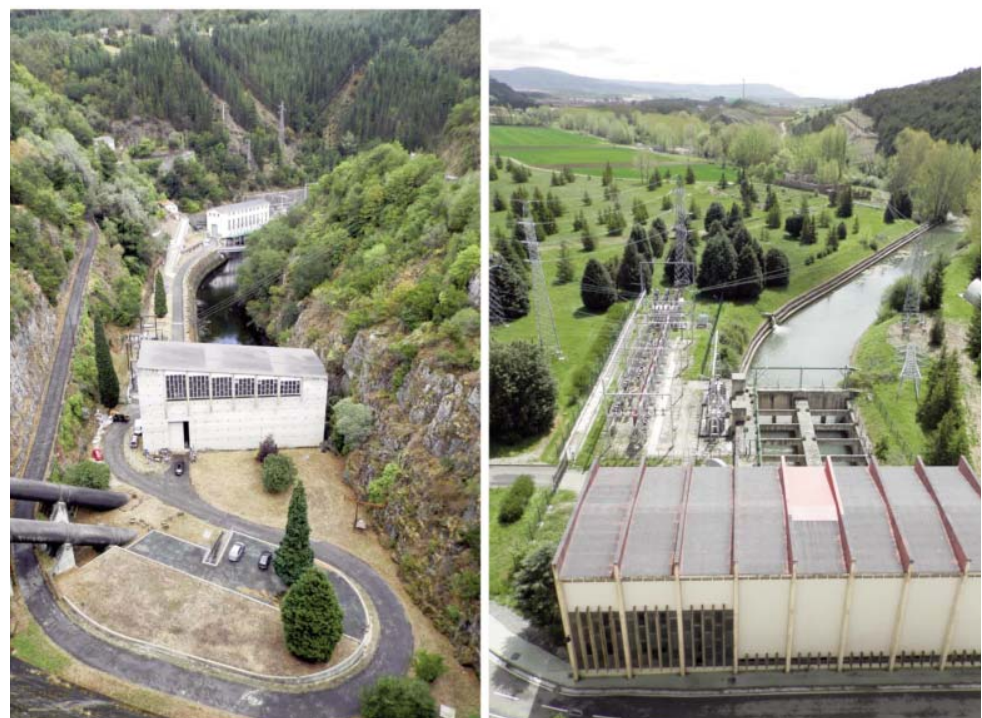

una entidad por sí sola, mientras que en Silvón y Aguilar la cercanía entre ambos permite un juego de doble escala, desde lo más cercano a pie de presa hasta la linea del horizonte que se abre en la coronación del muro (figura 24).

\section{Conclusiones}

Desde los dibujos de SantElia (1913-1914)18 o las experiencias de Hans Poelzig en la presa de Klingenberg (Biraghi 1992: 16), de principios del siglo XX, hasta la central hidroeléctrica de aires deconstructivistas de Becker Architekten (Kempten, Alemania; 2011), la arquitectura contemporánea se ha interesado continuamente por las construcciones industriales. Trabajar para la imbricación en su conjunto de los elementos paisajísticos, estéticos, técnicos y funcionales propios de una obra de arquitectura pero aplicados a una fábrica hidráulica, con todas las connotaciones que ello conlleva, ha constituido uno de los ámbitos de acción más característicos de la arquitectura de la contemporaneidad. No estamos hablando de ingeniería arquitectónica o de arquitectura industrial, sino de algo que va más allá y trasciende las simples formas industriales funcionales para convertirse en una obra de arte integradora que actúa sobre un entorno espectacular y a una escala gigantesca.

De entre todos los paisajes que han producido las actividades industriales, la construcción de presas para el aprovechamiento hidráulico es, probablemente, la que mayor impacto genera en el entorno. Las enormes paredes de hormigón o piedra que cierran los valles para embalsar el agua (que se encauza como un torrente a través de los aliviaderos y de las compuertas) constituyen, por su verticalidad, su potencia visual y sus evocaciones sonoras, uno de los elementos más interesantes a los que se tienen que enfrentar los técnicos a la hora de la construcción de este tipo de ingenios hidráulicos. Como ha señalado Carlos Fernández Casado: "la obra de ingeniería se proyecta en el paisaje, ostentando las formas más puras y simples. Debe destacar como el menhir, verticalidad que da acogida al hombre" (Fernández 2005: 32).

Otro rasgo significativo de estas obras es el hecho de que han sido concebidas en colaboración entre arquitectos e ingenieros. Y no es que sea éste un caso aislado: Antonio Palacios y Carlos Mendoza en Mengíbar (1913-1916), Luciano Yordi y Juan Castañón de Mena en Belesar (1959-1963), Miguel Fisac y Conrado Sancho Rebollido en Ip (1965-19671) ... Todos ellos destacan de entre los demás por haber sabido extraer de lo meramente funcional un lenguaje estético 
que los singulariza a cada uno de un modo particular y único. Sin duda, la colaboración entre distintos profesionales en un equipo multidisciplinar que lleva de la mano una obra conjunta y coherente resulta mucho más fructífera, satisfactoria y apasionante. Le Corbusier, en su libro La Maison des hommes comentaba que "ni siquiera en el caso de una tarea totalmente técnica como la construcción de un embalse debería estar ausente la figura del arquitecto" (Le Corbusier 1942: 136). Vicente Temes, en un número monográfico de la Revista Nacional de Arquitectura dedicada a las presas, también señala la necesidad de colaboración entre arquitectos e ingenieros en la construcción de aprovechamientos hidroeléctricos. ${ }^{19}$ Como dice Teodoro Anasagasti: “¿Cómo podrán concebirse con el debido acierto las construcciones industriales? La respuesta es categórica. No cabe duda que proyectándolas unidos el ingeniero y el arquitecto" (Anasagasti 1914: 154).

Por último, hay también que tener en cuenta el momento histórico en el que se construyeron estas centrales hidroeléctricas. La fuerte inversión en obras hidráulicas promovida desde las altas esferas del régimen en los años cincuenta y sesenta estimuló no sólo a las compañias a emprender la construcción de un elevado número de centrales, sino también a los técnicos, arquitectos e ingenieros de prestigio, a desarrollar nuevas formas de expresión en este ámbito. Éstos, contratados por unas empresas eléctricas que buscaban construir una nueva imagen representativa que les otorgara visibilidad y los diferenciara del resto, dedicarán por ello una especial atención al diseño de los propios contenedores, cuando en realidad lo más importante en esta clase de construcción industrial es, naturalmente, su contenido y su dimensión tecnológica. Todas estas circunstancias terminaron traduciéndose en la culminación de obras industriales de extraordinaria singularidad, y de una belleza y modernidad incuestionables que, alejadas del rigor de la arquitectura oficial del tiempo de la Dictadura, se adhieren sin disimulos a los lenguajes de la contemporaneidad, continúan vigentes más de cincuenta años después de su construcción 20 y pueden y deben ser reivindicadas como una parte substancial de la Historia de la Arquitectura y del Patrimonio Industrial en España. Contemplar hoy estas imponentes obras de arquitectura que son las centrales de Arenas de Cabrales, Arbón, Silvón o Aguilar de Campoo, nos hace evocar las palabras de Filippo Tommaso Marinetti cuando, en su obra La Splendour Géometrique et Mécanique (1914), señala: "nada en el mundo es más bello que una central eléctrica en funcionamiento, que retiene las presiones hidráulicas de toda una cordillera montañosa y la energía eléctrica para todo un paisaje, sintetizadas en cuadros de mando en los que surgen palancas y brillan los interruptores".

\section{Notas}

1. Natalia Tielve hace mención a estos edificios en sus libros de 2007 (El Salto de Grandas de Salime. Arte e Industria) y 2009 (Arquitectura Moderna en la Central de Soto de Ribera. La obra de Ignacio Álvarez Castelao y Carlos Fernández Casado) y en un artículo en 2011 (Arte, diseño y arquitectura industrial en la labor de Joaquín Vaquero Palacios), pero no es el objeto general del estudio. En la revista Ábaco Miguel Ángel Garcia-Pola Vallejo ( $\left.{ }^{\circ} 34,2002\right)$ hace un interesante análisis de las centrales hidroeléctricas asturianas, haciendo igual hincapié en las obras de Castelao que en las de Joaquín Vaquero Palacios, pero apenas sí menciona la central de Aguilar de Campoo. La principal fuente de información en cuanto a revistas son las publicaciones que los propios autores firman en las revistas Arquitectura y Cuadernos de Arquitectura (1960 y 1962) sobre Silvón y Arenas de Cabrales.

2. Nuestro más sincero agradecimiento a D. José Arroita-Jáuregui Sáinz, técnico de E.On por facilitarnos toda la información necesaria para la elaboración de este trabajo.

3. De este periodo destacan la construcción de la central de Puente Viesgo, en el río Pas y del Salto de Urdón en el desfiladero de La Hermida (Madrazo 1981: 32-35).

4. En la página web de E.on se puede encontrar más información sobre la historia de la compañia: http://www.eonespana.com/es/empresa/perfil/historia.

5. En 1926, Castelao se traslada a Madrid desde su Asturias natal y comienza los estudios de Ingeniero de Caminos donde, presumiblemente, debió conocer a Elorza. Finalmente, optará por el ingreso en la Escuela de Arquitectura, obteniendo el título el 14 de agosto de 1936, el cual tendrá que sustituir, tras la Guerra Civil por otro con fecha 14 de febrero de 1940 (Nanclares 1983: 45)

6. Fue además oficial del Cuerpo de Ingenieros del ejército franquista durante la guerra civil, y proyectó diversos puentes y fortificaciones que le permitieron adiestrarse en las técnicas estructurales y constructivas (San Marcos y Siñeriz 1983: 10).

7. Castelao y Elorza también colaboraron en la Central Nuclear de Garoña, Burgos (1965). Además, Castelao proyectó, junto a Carlos Fernández Casado, la central térmica de Soto de Ribera, otro hito de la Arquitectura Industrial asturiana. (Garcia-Pola 2002: 93-102)

8. La Ruta del Cares, en el concejo de Cabrales, se abrió en la roca para el mantenimiento del canal de alimentación de la central hidroeléctrica de Camarmeña - Poncebos. Esta fue la primera obra de Electra de Viesgo en Asturias (Tielve 2009: 14). El canal fue inicialmente construido entre el año 1916 y 1921, y posteriormente ampliado entre 1945 y 1950.

9. A quien, según relata Fernando Nanclares, conoció Castelao en los años 50 en sus continuos viajes y asistencias a Congresos (Nanclares 1983: 46).

10. El artista gijonés Antonio Suárez se encargó de los murales y vidrieras de las centrales de Silvón y Arenas de Cabrales. Castelao recurrió a él porque, según su criterio, era el único pintor que en esos momentos realizaba arte aplicado con un sentido integrador. Colaboraron juntos también en otras obras tan significativas del arquitecto como la Delegación de Hacienda (1960), o la Facultad de Ciencias Geológicas y Biológicas (1965), ambas en Oviedo (Gago 2008: 40-41).

11. La vidriera se ejecutó in situ por el elevado coste 
que suponia su transporte hasta un lugar tan alejado y poco accesible. El plástico que se utilizó provenía de Bélgica, en un intento por parte de Suárez de innovar en el uso de nuevos materiales (Gago 2008: 67)

12. El tratamiento compositivo dispone tramos en los que se unen trozos con diferentes tonalidades de un mismo color junto a otros en los que destaca el contraste entre colores complementarios. Además, la estructura se potencia por el uso de las diagonales (Gago 2008: 66)

13. Es tal la importancia de este edificio, que se trata de la única central española seleccionada por la Commissioner Research Bureau of Reclamation, Dept. of the Interior, de Washington, como una de "Catedrales de la Energia” (San Marcos y Siñeriz 1983: 10).

14. Curiosamente, estos elementos prefabricados son muy parecidos a los que utiliza Miguel Fisac para la fachada de su edificio de oficinas para IBM en Madrid. Ambos proyectos son casi simultáneos, por lo que es casi imposible determinar cual de los dos se adelantó al otro con esta clase de solución.

15. Posteriormente y ya en solitario Elorza, como Director de Construcción de Electra de Viesgo, proyectó la central de Aguayo (1978-1982) como parte del aprovechamiento hidroeléctrico generado al recrecer unos 7 metros la antigua presa de Alsa, en Bárcena de Pie de Concha (Cantabria) (Elorza 1985: 369).

16. En este sentido, el arquitecto más directamente relacionado con Castelao, sería Joaquín Vaquero Palacios (Oviedo, 1900 - Madrid, 1998), también pintor y escultor, por su coincidencia en el tiempo (aunque Palacios pertenece a una generación anterior, ambos construyeron sus obras más significativas entre los años 50 y 70), y en el espacio (ambos son asturianos y en esa región desarrollaron casi toda su labor profesional). En las centrales que Vaquero diseña para Hidroeléctrica del Cantábrico conjuga los aspectos funcionales con los artísticos, dando así una hermosa lección sobre las posibilidades del arte para humanizar y dignificar espacios que de otro modo resultarian anodinos. Se trata de obras ejemplificadoras del diálogo pasado-futuro, de la complementaridad MetafísicaFuturismo, con unos interiores donde la máquina es valorada como escultura y con un encomiable afán didáctico en los murales decorativos (Pérez 1992: 85)

17. Se trata de una crítica, no demasiado velada, a las abigarradas representaciones murales con que Vaquero Palacios y su hijo Vaquero Turcios decoraban los interiores de las centrales hidroeléctricas que diseñaron para Hidroeléctrica del Cantábrico: Grandas de Salime, Proaza, Miranda y Tanes.

18. "En sus dibujos de centrales eléctricas se aprecian algunos elementos definitorios de su uso, como turbinas, presas y desniveles, así como grandes tendidos de cableado que se prolongan más allá del edificio, en un intento de establecer el punto inicial de la red que comunica la central con la ciudad" (Kliczkowski 2003: 39).

19. "El planteamiento, la dirección y la construcción de estas obras, como es sabido, son trabajos propios de los ingenieros; pero su envergadura y la multiplicidad e importancia de sus aspectos exigen hoy la colaboración, en equipo, de técni$\cos \mathrm{y}$ especialistas de distintas profesiones, entre ellos los arquitectos" (Temes 1954: 15).

20. Por otra parte, en este tipo de arquitectura industrial no es frecuente encontrar edificios que hayan perdido su uso o hayan sido declarados ruinosos, porque a las empresas eléctricas les interesa que se mantengan en perfecto estado de conservación durante los periodos de concesión.

\section{Bibliografia}

Aguiló, Miguel. 2005. La enjundia de las presas españolas. $2^{\mathrm{a}}$ ed. Madrid: ACS

Aguiló, Miguel. 2006. La pujanza de la energía eléctrica en España. Madrid: ACS.

Álvarez Castelao, Ignacio y Elorza, Juan José. 1960 Salto de Silvón y Salto de Arenas. Cuadernos de Arquitectura, 41: 343-345.

Álvarez Castelao, Ignacio y Elorza, Juan José. 1962. Saltos de Arenas de Cabrales y Silvón. Revista Arquitectura COAM , 47: 23-26.

Anasagasti, Teodoro. 1914. El arte de las construcciones industriales. Revista de Arquitectura y Construcción, 263: 150-155.

Arancón, Gerardo. 1998. Viviendas de la Eléctrica de Aguilar de Campoo. En: Garcia Braña, Celestino y Agrasar Quiroga, Fernando (eds.), Arquitectura Moderna en Asturias, Galicia, Castilla y León. Ortodoxia, Márgenes y Transgresiones. Gijón: Colegio Oficial de Arquitectos de Asturias. 256257.

Biraghi, Marco. 1992. Hans Poelzig: architectura, ars magna. 1869-1936. Venecia: Arsenale.

Elorza, Juan José. 1985. Aguayo y su depósito superior. Revista de Obras Públicas, 3236: 369-372.

Fernández Casado, Carlos. 2005. La Arquitectura del Ingeniero. $2^{\mathrm{a}}$ ed. Madrid: Colegio de Ingenieros de Caminos, Canales y Puertos.

Fuentes Quintana, Enrique. 1988. Tres decenios de la economía española en perspectiva. En: García Delgado, José Luis (coord.), España economía. Madrid: Espasa Calpe. 1-78

Gago, Ana. 2008. El arte de Antonio Suárez aplicado a la Arquitectura. Gijón: Museo de Bellas Artes de Asturias y Museo Casa Natal de Jovellanos.

García Braña, Celestino, Landrove, Susana y Tostoes, Ana. 2005. La arquitectura de la industria, 19251965: registro DOCOMOMO ibérico. Barcelona: Fundación DoCoMoMo Ibérico.

Garcia-Pola Vallejo, Miguel Ángel. 1997. Asturias, la épica del desarrollo. La obra de Joaquin Vaquero Palacios, Ignacio Álvarez Castelao e Ildefonso Sánchez del Río. Quaderns, 215: 92121.

García-Pola Vallejo, Miguel Ángel. 2002. Arte, arquitectura, ingenieria y paisaje en las centrales hidroeléctricas asturianas. Revista Ábaco, 34: 93-102.

Kliczkowski, H. 2003. Antonio Sant'Elia. Barcelona: LOFT Publications.

Le Corbusier y Pierrefeu, François. 1942. La Maison des hommes. París.

Madrazo Feliú, Baldomero. 1981. Electra de Viesgo, 75 años. Santander: Electra de Viesgo S.A.

Marinetti, Filippo Tommaso. 1914. La splendeur géometrique et mécanique et la sensibilité numérique: manifeste futuriste. Milán: Direction du mouvement futuriste.

Mateos, Abdón y Soto, Álvaro. 1997. El final del franquismo, 1959-1975. La trasnformación de la sociedad española. Madrid: Historia 16 / Temas de Hoy.

Nanclares, Fernando. 1983. Ignacio Álvarez Castelao. Obradoiro, 8: 45-51.

Nanclares, Fernando y Ruiz, Nieves. 2014. Lo moderno de nuevo. Arquitectura en Asturias 1950 1965. Madrid: Lamicro.

Pérez Lastra, José Antonio. 1992. Vaquero Palacios, Arquitecto. Oviedo: Colegio Oficial de Arquitectos de Asturias.

San Marcos Espinosa, Juan Ignacio y Siñeriz Triviño, Julio (coord.). 1983. Ignacio A. Castelao, Arquitecto [catálogo exposición]. Oviedo: Colegio Oficial de Arquitectos de Asturias.

Temes, Vicente. 1954. La arquitectura en los aprovechamientos hidroeléctricos. Revista Nacional de Arquitectura, $\mathrm{n}^{\circ}$ 147, marzo.

Tielve García, Natalia. 2007. El Salto de Grandas de Salime. Arte e Industria. Gijón: CICEES.

Tielve Garcia, Natalia. 2009. Arquitectura Moderna en la Central de Soto de Ribera. La obra de Ignacio 
Álvarez Castelao y Carlos Fernández Casado. Gijón: CICEES.

Tielve García, Natalia. 2011. Arte, diseño y arquitectura industrial en la labor de Joaquín Vaquero Palacios (1900-1998). NORBA Revista de Arte, 31: 111-131.

Tusell, Javier. 1996. La dictadura de Franco. Madrid: Ediciones Altaya.

Vittorini, R. 1998. L'architettura delle centrali tra classicismo e funzionalismo. En Pavia, Rosa (ed.). Paesaggi elettrici, territori, architetture, culture. Venecia: Marsilio.

Fecha de aceptación:

$15 / 06 / 15$

Articulo sometido a revisión por dos revisores independientes por el método doble ciego. 